\title{
Neuropsychological and psychosocial consequences of minor head injury
}

\author{
SUREYYA DIKMEN, ALVIN MCLEAN, NANCY TEMKIN \\ From the Departments of Rehabilitation Medicine, Neurological Surgery, Biostatistics and Psychiatry and \\ Behavioral Sciences, University of Washington, Seattle, Washington, USA
}

SUMMARY Twenty subjects with minor head injury were compared to an uninjured group at 1 and 12 months after injury on a battery of neuropsychological and psychosocial measures. The results indicate that single minor head injury in persons with no prior compromising condition is associated with mild but probably clinically non-significant difficulties at 1 month after injury. Disruptions of everyday activities, however, are extensive with other system injuries significantly contributing to these problems. Recent reports in the literature may represent overestimation of head injury related losses due to lack of control for the effects of pre-injury characteristics and other system injuries.

Interest in minor head injury has existed for some time, owing to the high incidence rate with which it occurs and the relatively high morbidity associated with it. A major research focus of the past was on the post-concussional symptoms and why they persisted in some cases (see refs 1 and 2 for reviews). More recent investigations have attempted to identify additional sequelae, such as neuropsychological and psychosocial, and determine the time course for natural recovery from such consequences. There has been a strong interest in neuropsychological consequences based on the belief and the hope that they would provide objective evidence of impaired brain functions and, therefore, explain patients' subjective complaints and disruptions in psychosocial functioning.

Significant impairment of neuropsychological functions, in the absence of other positive neurological findings, do in fact seem to occur within days of minor head injury. ${ }^{3-5}$ The main question is how long do these difficulties last. Persistent neuropsychological and psychosocial difficulties at 3 months after minor head injury were reported in the well known studies by Rimel et $a l^{6}$ and Barth et $\mathrm{al}^{7}$ which were based on the same subject pool. The results of several other studies, however, have indicated more optimistic neuropsychological outcome by about 1 month after minor head injury. ${ }^{3458}$

Address for reprint requests: Sureyya Dikmen, $\mathrm{PhD}$, Rehabilitation Medicine RJ-30, University of Washington, Seattle, WA 98195, USA.

Received 12 November 1985. Accepted 15 December 1985
These discrepant findings warrant more careful scrutiny. The neuropsychological results for the group studied by Rimel et $\mathbf{l}^{6}$ were indeed impaired as compared with normative standards. However, in the absence of a proper comparison group, it is difficult to sort out the contribution of head injury as contrasted with the contribution of other factors which could influence neuropsychological functions (for example, premorbid characteristics, method of case selection).

The purpose of the present study was to carefully delineate the effects of minor head injury. In an effort to achieve this purpose, a number of important methodological considerations and other factors were taken into account. These included: (1) the selection of consecutive cases as opposed to cases seen for clinical reasons; (2) the administration of an extensive battery of both neuropsychological and psychosocial measures; (3) the attainment of a $95 \%$ follow up rate; (4) the utilisation of a control group comparable with the head injured subjects; and (5) the examination of the contribution of other system injuries (for example, orthopaedic problems) in the same accident.

\section{Method}

Subjects
Head injured group. The head injured subjects consisted of
20 consecutive patients who were hospitalised at Har-
borview Medical Center, Seattle, Washington from October
1980 to March 1982 who met the following criteria:
(1) Any period of coma not to exceed 1 hour, or if no
coma, post-traumatic amnesia of at least 1 hour
(2) Glasgow Coma Scale $\geqslant 12$ on admission
(3) No clinical evidence of cortical or brain stem contusion 
(4) No history of prior head injury, alcoholism, cerebral disease, mental retardation or significant psychiatric disorder

(5) Age range between 15 to 60 years at the time of injury

(6) English speaking

(7) Willingness to participate and residence that would allow availability for 1 and 12 month follow ups.

Nineteen of the 20 subjects of the present study were seen for 1 and 12 month follow up examinations. One subject was examined at 1 month but did not return for the 12 month examination. These subjects were part of a group of 102 cases who were participants in a comprehensive head injury study. The members of this larger group met criteria 4 to 7 and represent a broad spectrum of head injury severity ranging from mild to very severe. Other system injuries, including orthopaedic problems, were not a cause for exclusion of patients from this study. Ten cases had orthopaedic injuries and one case had soft tissue injuries. Three patients were litigating. Seven of the subjects in the present investigation were also subjects in a prior study by our research group. ${ }^{4}$ Uninjured group The 19 uninjured subjects were selected from friends of the patients in the larger head injured group. They were individually matched for age, education, and sex. Subjects with past or present evidence of CNS disease, including alcoholism, were excluded from this group as well. Table 1 presents basic demographic information including age, education, and sex for the head injured and uninjured groups.

\section{Measures}

An extensive battery of neuropsychological and psychosocial measures was administered to the head injured subjects at 1 and 12 months after injury. The uninjured subjects were also tested on the same measures with the same testretest interval.

Neuropsychological measures The Halstead-Reitan Neu-
Table 1 Demographics

\begin{tabular}{lll}
\hline & Head injury & Uninjured \\
\hline Mean age & $25 \cdot 3$ & $25 \cdot 5$ \\
Education & $13 \cdot 0$ & $12 \cdot 6$ \\
Sex & 11 & 11 \\
$\quad$ Males & 9 & 9 \\
Females & & \\
\hline
\end{tabular}

ropsychological Test Battery and some additional measures of memory were administered. ${ }^{9-11}$ The list of the measures and general areas of function they assess are provided in table 2. Most of these measures have been used extensively in prior research, including in the area of head injury. ${ }^{91213}$ The abilities assessed by these measures range from relatively simple to quite complex (for example, from simple motor skills to abstract thinking). These tests have been shown to be sensitive to the effects of various brain lesions and neurological conditions including head injury.

Psychosocial measures The three behavioural/psychosocial measures used were the Sickness Impact Profile, ${ }^{14}$ the Head Injury Symptom Checklist and a modification of the Function Status Index. ${ }^{1516}$ The Sickness Impact Profile measures health status in terms of sickness related changes in various areas of living (for example, sleep and rest, emotional behaviour, social interaction, alertness behaviour, and recreations and pastimes). The Head Injury Symptom Checklist (HISC) evaluates a set of 12 symptoms that are frequently reported as part of the sequelae of traumatic head injury (for example, headaches, fatigue, memory difficulties, irritability). Resumption of major activities (that is, work, school, homemaking) and other activities (for example, leisure and pastimes) are portions of the Modified Function Status Index used. All these measures in the psychosocial area rely on the subjects' report of changes in functioning or performance

Table 2 Median scores on the neuropsychological measures. One-month evaluations

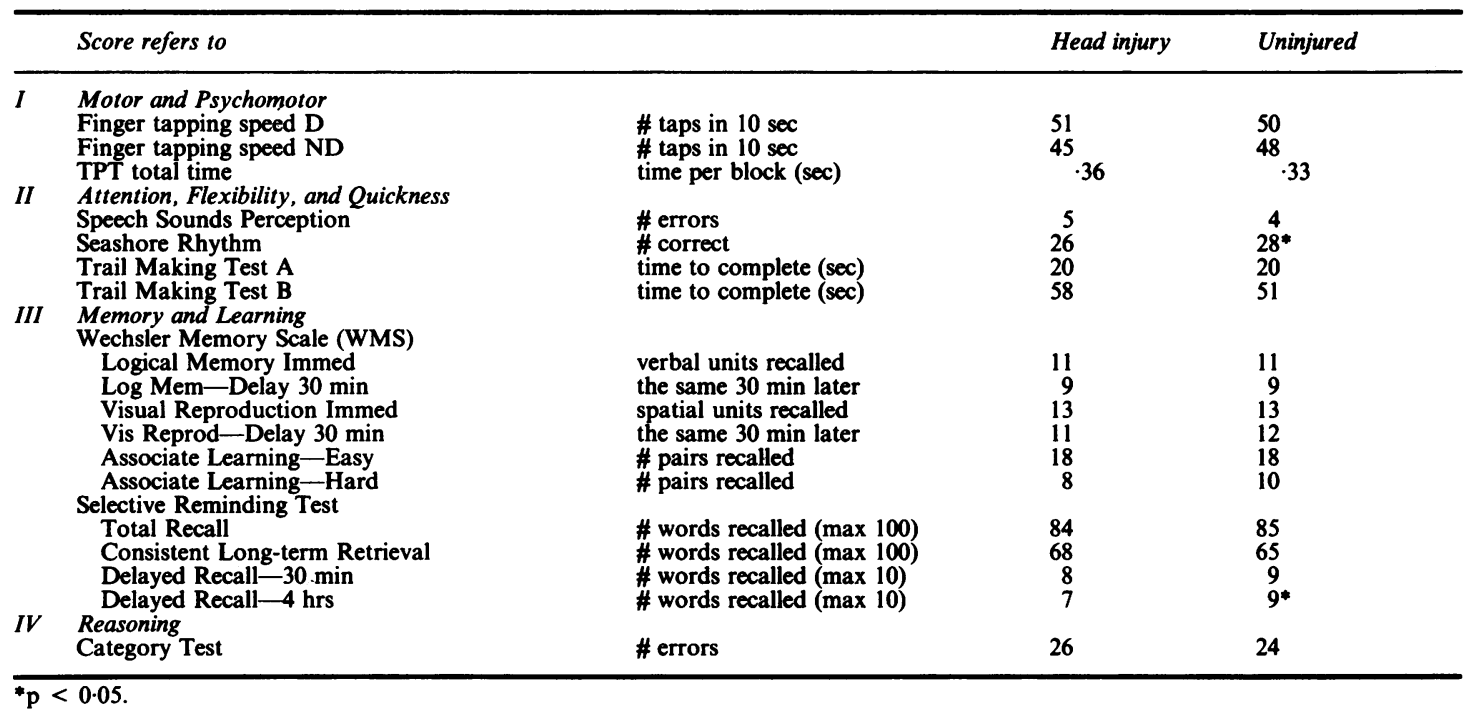


due to head injury and health. In contrast, the neuropsychological measures are based on objective examination of cognitive status and other basic adaptive abilities.

\section{Data analysis}

Wilcoxon Signed Rank tests were used when the head injured-uninjured pairs were compared on the neuropsychological measures and the Sickness Impact Profile. A test for equality of dependent proportions (McNemar's test) was used to compare symptom endorsement in the pairs of subjects.

\section{Results}

\section{Neuropsychological measures}

Table 2 presents the median neuropsychological test scores of the head injured and uninjured subjects at 1 month after injury. Inspection of the scores indicates that the performances of both the head injured and uninjured groups are quite good as compared to normative data and results from other published head injury studies. ${ }^{67}$ There is a trend, however, for the head injured group to perform a little less adequately as compared with the uninjured group, with the differences reaching significant levels on two of the 21 measures. The head injury group performed significantly poorer than the uninjured group on the Seashore Rhythm Test, a measure requiring concentration and discrimination between rhythmic patterns. Additionally, the head injured subjects did significantly worse in remembering newly learned information after a 4 hour delay on the Selective Reminding Test.

At 1 year after injury, none of the neuropsychological measures evidenced significant differences.

The results presented generally indicate that the performances of the head injury group were not impaired in a clinical sense, but were slightly lower than those of the uninjured group.

\section{Psychosocial measures}

Daily activities Figure 1 presents the mean percent dysfunction of the head injury subjects at 1 and 12 months after injury on the Sickness Impact Profile. The scores are based on the subjects' perception of the extent to which their injuries and/or other health problems have affected their day to day functioning. The results on this test can be summarised as follows. First, there is a significant amount of dysfunction at 1 month after injury across different categories ranging from physical type of abilities (for example, ambulation, body care and movement) to higher level functioning (for example, emotional behaviour, alertness behaviour, social interactions) and to major role activities (for example, home management, work). On every subscale but eating, the head injury

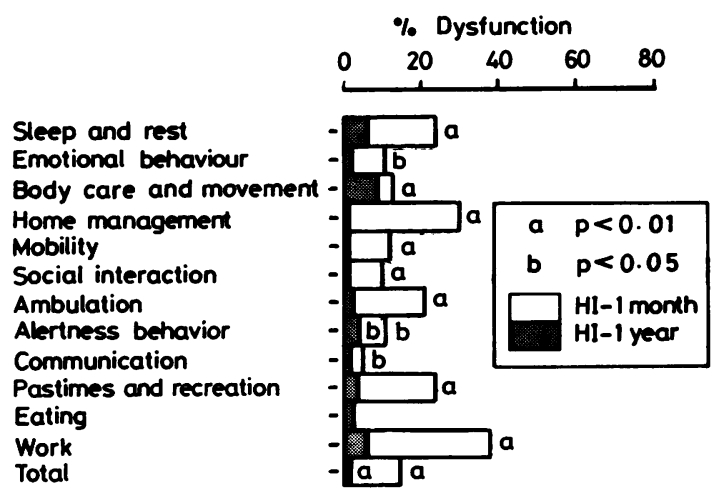

Fig 1 Mean percent dysfunction on the Sickness Impact Profile (SIP).

group reported significantly greater health-related difficulties than did the uninjured subjects. The uninjured subjects' results are not presented in this figure because their mean SIP scores were essentially zeros for all subscales. Second, as the results from fig 1 indicate, on each scale there is a definite decline in the amount of dysfunction by 1 year. Note that at both 1 month and 1 year cognitive and emotional difficulties are not the most frequently endorsed problems.

Table 3 shows the results relating to resumption of major role (that is, work, school, home management) and leisure activities. The results at 1 month indicate that most patients either have not resumed such activities or if they have, they are performing them with limitations. At 1 year, however, most have returned to their major role activities and resumed their leisure/recreational activities, although some continued to perform them with limitation.

\section{Contribution of other system injuries}

Eleven of the 19 subjects with minor head injury had orthopaedic or soft tissue injuries sustained in the

Table 3 Resumption of major and other activities

\begin{tabular}{lcc}
\hline Modified Function Status Index & I month & l year \\
\hline Return to Major Activity & & \\
With no limitations & 4 & 15 \\
With limitations & 4 & 2 \\
No return & 9 & $2^{*}$ \\
Could not determine-summer & 2 & 0 \\
Resumption of Leisure/Recreational & Activity & \\
With no limitations & 3 & 12 \\
With limitations & 15 & 6 \\
No resumption & 1 & 0 \\
No resumption, not injury related & 0 & 1
\end{tabular}

*One of the two head injury cases not returned at one year, was not head injury related. 
Table 4 Contribution of other system injuries (for example, orthopaedic and soft tissue injuries) at 1 month after injury

\begin{tabular}{lll}
\hline & $\begin{array}{l}\text { Head injury } \\
\text { only }\end{array}$ & $\begin{array}{l}\text { Head injury }+ \\
\text { other injuries }\end{array}$ \\
\hline Work/School & $(8)$ & $(11)$ \\
Not applicable & 0 & 1 \\
Without limitations & 3 & 1 \\
With limitations & 4 & 0 \\
Not doing & 1 & 9 \\
Leisure Activity & & \\
Without limitations & 3 & 0 \\
With limitations & 5 & 10 \\
Not doing & 0 & 1 \\
\hline
\end{tabular}

same accident. Table 4 presents the number of subjects with and without other system injuries resuming their major (work/school) and leisure activities at 1 month post injury. The results indicate that other system injuries do contribute to limitations of psychosocial functioning. Note that nine of 11 subjects with head injury plus other system injuries were not working or going to school in contrast to one of eight of those with head injury alone. With respect to leisure activities, 10 of 11 subjects with head injury plus other injuries versus 5 of 8 of these with head injury alone were performing leisure activities with limitations. At 1 year after injury, most subjects had resumed their major and leisure activities as previously presented in table 3.

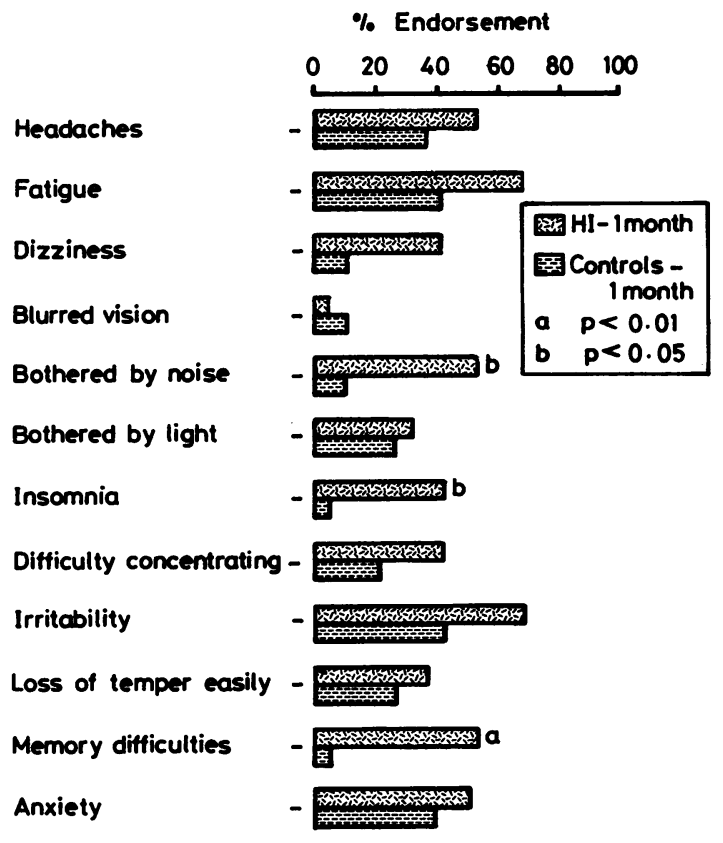

Fig 2 Median percent endorsement on the Head Injury Symptom Checklist (HISC).
Post-traumatic symptoms

Figure 2 shows the results for the head injury symptom checklist (HISC). Presented are the percentages of subjects in the head injury group endorsing each symptom at 1 month after injury as compared with the percentages of uninjured subjects reporting such problems. The results on this measure indicate that (1) these symptoms are common, even in people who have not had head injuries; (2) head injured subjects endorse more of such difficulties than uninjured subjects at 1 month after injury; and (3) by 1 year after injury, the groups are not different from one another.

\section{Discussion}

The neuropsychological portion of the study was directed at determining minor head injury related deficits at 1 and 12 months after injury. To that end, patients with pre-existing conditions were excluded from the study and an uninjured comparison group consisting of friends of the patients was used. Compared with published norms for detecting brain disorders, the head injury group performed quite well at both 1 month and 12 months after injury. However, when compared to uninjured subjects, they tended to perform a little less well with significant differences occurring on two measures at 1 month after injury. Our results represent more of a trend than a definitive finding of decreased abilities. This suggestion is particularly evident when one considers the number of significant findings with the number of comparisons made and the possibility of somewhat lower premorbid abilities of the head injured patients as compared with the uninjured group (for example, nonsignificant but nevertheless lower VIQ, 102 vs 108 , respectively). The neuropsychological results of the current study are consistent with those of three prior controlled studies based on the performances of patients with minor head injury at 1 month after injury. ${ }^{458}$

The results of the present study are inconsistent, however, with some other studies especially the widely known Rimel et al study. Direct comparison of the neuropsychological results are possible since some of the same measures were used in both studies. Furthermore, in spite of some differences in severity criteria used for subject selection, both samples were quite mild. The neuropsychological performances of their sample at three months after injury was worse than those of the current sample as well as being worse than published norms for detecting brain disorders. This led them to conclude that minor head injuries have a significantly impairing effect on higher level brain functions. Possible reasons for the differences in the results and the conclusions drawn between the 
current study and Rimel et al study may include method of case selection and the criteria against which head injury effects were determined. In their study, patients with pre-existing conditions involving the central nervous system (for example, prior head injuries, other neurological conditions) were not excluded. They were, however, from the current sample. In fact, Rimel et al reported that $31 \%$ of their larger series had prior head injuries. Inadvertent bias in the selection of cases subjected to neuropsychological examination is another possible source of error. Less than one-fifth of the consecutive minor head injured patients were examined with the neuropsychological measures in their study. Even though a random sample may have been the intention, it is possible that those needing or those who could have benefited from such a service may have ended up being the ones examined. Both of these procedures are likely to lead to selection of cases with poorer neuropsychological functions. Thus, their poor performances may not have been entirely caused by the head injury under consideration or be representative of performances of minor head injury in general. Another point of difference between the Rimel et al study and the current study is that in the Rimel study, normative data rather than comparison group data were used to determine head injury effects. The normative data are based on group norms which differ from the head injured group on factors such as age, education, job status, no pre-existing conditions (that is, dimensions which affect neuropsychological performances). Sampling methods or artifacts leading to overestimation of problems and failure to properly control for such effects may be responsible, then, for the differences in results and conclusions drawn between the studies. It should be noted, however, that the results of their study point out the difficulties experienced by some head injured patients who have sustained a minor head injury, a population which needs clinical attention and intervention. However, their study allows for limited generalisations regarding neuropsychological impairments caused by minor head injury.

Significant disruption of psychosocial functions was observed especially at 1 month after injury (for example, leisure, work, social interactions, ambulation, sleep, and rest). However, a definite decline in the amount of disruption was observed by 1 year in all areas. The reason for these disruptions does not appear to be related solely to the head injury. Other system injuries (for example, orthopaedic problems) which are often sustained in the same accident, appear to be responsible, in part, for the psychosocial disruptions observed. Minor head injury by itself does have some negative consequences as reflected in significantly greater difficulties in the resumption of leisure activities (see table 4). However, other system injuries seem to add significantly to the disruption including affecting resumption and performance of major activities (work/school) and leisure activities. It is noteworthy that 9 of 11 cases with additional other injuries were not working (or going to school) at 1 month after injury in contrast to 1 of the 8 with minor head injury alone. Finally, the amount of dysfunction at 1 year is fairly low in our sample of consecutive cases.

Our results relating to the post concussional symptoms (PCS) are in line with those reported by others. ${ }^{17-21}$ Such symptoms are very common and they do decline with time. The more interesting finding, as we previously have reported, is the endorsement of the same problems by the uninjured subjects, an observation made earlier by Caveness. ${ }^{22}$ Some of these symptoms are common in both the injured and the uninjured subjects (for example, headaches, fatigue) while others seem to occur more frequently among the injured subjects at 1 month after injury (for example, sensitivity to noise, complaints of memory problems, and disturbance of sleep). By 1 year, there is no evidence for greater problems of the injured over the uninjured subjects.

The results of our study and those of others indicate that patients with minor head injury experience a multitude of behavioural difficulties following their accidents. However, these difficulties which improve over time, cannot be solely attributed to the head injury. Given consecutive cases without compromising pre-existing conditions, neuropsychological deficits which are experienced early seem to largely disappear for the group by 1 month after injury. This conclusion is based on the results of the present and three other controlled studies. ${ }^{458}$ Other system injuries in addition to the head injury contribute significantly to the disability observed in everyday types of activity such as resuming work, leisure activities, and more straightforward physical functions. These, again, largely disappear by 1 year. Posttraumatic symptoms, on the other hand, occur frequently and persist for a longer time period. However, they are not entirely specific for head injury. Even though some of these symptoms occur more frequently among head injured patients, they are subjective and common even in people who have not had head injuries. In other words, just because patients report them does not mean that they can be considered as reliable diagnostic measures of head injury. The general behavioural trends described here apply to consecutive cases with minor head injury and without compromising pre-existing conditions. They also apply to groups and to previously healthy young people. There are those individual cases who continue to experience post-traumatic sequelae over a much 
longer period of time. Numerous factors (for example, neurological, neuropsychological, physical, psychological, compensation) probably contribute to why they persist in some individuals. Each individual, then, needs to be evaluated for the contribution of these factors. In terms of the sequelae following minor head injury, however, these cases are the exception rather than the rule.

This study was supported by Grant No HS05304 from the National Center for Health Services Research, Office of the Assistant Secretary for Health, and Grant No G00-8300076, National Institute of Handicapped Research, Department of Education.

We thank Norma Dermond for her help in computing and Wilma Dlouhy in preparation of the manuscript.

\section{References}

${ }^{1}$ Trimble MR. Post-Traumatic Neurosis. New York: John Wiley \& Sons, 1981.

${ }^{2}$ Binder LM. Persisting symptoms after mild head injury: A review of the postconcussive syndrome. J Clin Exp Neuropsychol (in press).

${ }^{3}$ Gronwall D, Wrightson P. Delayed recovery of intellectual function after minor head injury. Lancet 1974;2:605-9.

${ }^{4}$ McLean A, Temkin NR, Dikmen S, Wyler AR. The behavioral sequelae of head injury. J Clin Neuropsychol 1983;5:361-76.

${ }^{5}$ Levin HS, Mattis S, Ruff RM, et al. Neurobehavioral outcome of minor head injury: a three center study. J. Neurosurg (in press).

${ }^{6}$ Rimel R, Giordani M, Barth J, Boll T, Jane J. Disability caused by minor head injury. Neurosurgery 1981;9:221-8.

${ }^{7}$ Barth JT, Macciocchi SN, Giordani B, Rimel R, Jane RA, Boll TJ. Neuropsychological sequelae of minor head injury. Neurosurgery 1983;13:529-33.

${ }^{8}$ Gentilini M, Nichelli P, Schoenhuber R, et al. Neuropsychological evaluation of mild head injury. $J \mathrm{Neu}$ rol Neurosurg Psychiatry 1985;48:137-40.

${ }^{9}$ Reitan RM, Davison LA (eds). Clinical Neuropsychology: Current Status and Applications. Washington DC: Winston \& Sons, 1974.

${ }^{10}$ Buschke $\mathrm{H}$. Selective reminding for analysis of memory and learning. $J$ Verbal Learn Verb Behav 1973;12:543-50.

${ }^{11}$ Wechsler D. A standardized memory scale for clinical use. $J$ Psychol 1945;19:87-95.

${ }^{12}$ Dikmen SD, Reitan RM, Temkin NR. Neuropsychological recovery in head injury. Arch Neurol 1983;40:333-8.

${ }^{13} \mathrm{~K}$ love $\mathrm{H}$, Cleeland CS. The relationship of neuropsychological impairment to other indices of severity of head injury. Scand J Rehabil Med 1972;4:55-60.

${ }^{14}$ Bergner M, Bobbitt RA, Pollard WE, Gilson BE. The Sickness Impact Profile: Validation of a health status measure. Medical Care 1976;14:57-67.

15 Patrick DL, Bush JW, Chen MM. Toward an operational definition of health. J Health Soc Behav 1973;14:6-23.

${ }^{16}$ Reynolds W, Rushing W, Miles D. The validation of a Function Status Index. $J$ Health Soc Behav 1974;15:271-88.

${ }^{17}$ Cook JB. The post-concussional syndrome and factors influencing recovery after minor head injury admitted to hospital. Scand J Rehabil Med 1972;4:27.

${ }^{18}$ Landy PR. The post-traumatic syndrome in closed head injuries and accident neurosis. Proc Austr Assoc Neurol 1968;5:463-6.

${ }^{19}$ Lidvall H, Linderoth B, Norlin B. Causes of the postconcussional syndrome. Acta Neurol Scand 1974;50:Suppl 56.

${ }^{20}$ Minderhoud JM, Boulens MEM, Huizenga J, Saan RJ. Treatment of minor head injuries. Clin Neurol Neurosurg 1980;82:127-40.

${ }^{21}$ Rutherford WH, Merrett JD, McDonald JR. Symptoms at one year following concussion from minor head injuries. Injury 1979;10:225-30.

${ }^{22}$ Caveness WF. Posstraumatic Sequelae. In: Caveness WF, Walker A, eds. Head Injury Conference Proceedings. Lippencott, 1966:209-19. 